\title{
STABILITY OF IMMOBILIZED BIOSORBENTS AND ITS INFLUENCE ON BIOSORPTION OF COPPER
}

\author{
DANA IVÁNOVÁ ${ }^{1}$, HEDVIGA HORVÁTHOVÁ ${ }^{2}$, \\ JANA KADUKOVÁ ${ }^{2}$, JANA KAVULIČOVÁ ${ }^{1}$ \\ ${ }^{1}$ Technical University of Košice, Faculty of Metallurgy, Department of Chemistry, \\ Letná 9, Košice, SK-040 13, Slovak Republic (dana.ivanova@tuke.sk) \\ ${ }^{2}$ Technical University of Košice, Faculty of Metallurgy, Department of Non-Ferrous \\ Metals and Waste Treatment, Letná 9, Košice, SK-040 13, Slovak Republic \\ (hedviga.horvathova@tuke.sk)
}

\begin{abstract}
Biomass immobilization in a polymeric matrix may improve biosorption capacity and facilitate the separation of biomass from metal-bearing solutions. Many polymers are studied as immobilizing agents for biosorption including biopolymers such as sodium alginate. In the article swelling behaviour of gel and dry beads has been studied in aqueous solutions with different acid-base character. Swelling of gel or dry calcium alginate beads was found in all acidic and basic solutions except of the gel beads in strong acidic solutions, which exhibited the tendency to shrink. Dry beads in diluted acidic solutions had the greatest stability because they exhibited minimum swelling. Dry and gel beads were completely dissolved in concentrated solutions of sodium and potassium hydroxides. The potential use of immobilized algal biomass in Ca-alginate beads for removal of copper ions from aqueous solution was also investigated. The results of the kinetic studies showed that the sorption of copper ions on gel immobilized beads are the most suitable.
\end{abstract}

Key words: Calcium alginate beads, $\mathrm{pH}$, stability, dissolution, swelling, biosorption, Chlorella kessleri

\section{Introduction}

Heavy metal pollution is one of the most important environmental problems today. One of the processes used for heavy metal removal from waste water and even their recovery can be biosorption that utilizes various natural materials of biologic origin (VOLESKY, 2003; KADUKOVÁ et al., 2008; WANG and CHEN, 2009).

Biosorption can be defined as the passive sequestering of metal ions by metabolically inactive biomass via various physicochemical mechanisms. Metal uptake may take place by different metal-binding mechanisms such as physical adsorption, chemisorption, ion exchange, microprecipitation, complexation, coordination, chelation (VOLESKY, 2003; KADUKOVÁ and ŠTOFKO, 2006; WANG and CHEN, 2009). For industrial application of biosorption, it is important to utilize an appropriate immobilization technique to prepare commercial biosorbents. Disadvantage of the free microbial cells used in laboratory conditions is that they are basically small particles, with low density, poor mechanical strength and little rigidity. In real application they may come up with the solid-liquid separation problems, possible biomass swelling, inability to regenerate/reuse and development of high pressure drop in the column mode. High pressures can cause disintegration of free biomass. The immobilization of the biomass in solid structures would create a biosorbent material with the right size, mechanical strength, rigidity and porosity 
necessary for use in practical processes. Various methods are available for biomass immobilization. These include entrapment in polymers, adsorption, cross-linking and covalent linkage (VOLESKY, 1990). The polymeric matrix determines the mechanical strength and chemical resistance of the final biosorbent particle to be utilized for successive sorption-desorption cycles (WANG and CHEN, 2009).

Important immobilization matrices used in biosorbent immobilization include sodium or calcium alginate. Alginate is a linear polysaccharide isolated from many strains of marine brown algae. Alginates constitute a family of unbranched binary copolymers of 1-4 linked $\beta$-D-mannuronic acid $(\mathrm{M})$ and $\alpha$-L-guluronic acid $(\mathrm{G})$ residues (VIJAYA et al., 2008; VREEKER et al., 2008).

The aim of this work was to study the stability of the different calcium alginate beads in acidobasic conditions with respect to application in biosorption and desorption experiments. The technical feasibility of using immobilized algal biomass for the removal of copper ions from aqueous solutions and the effect of beads preparation on kinetics of biosorption were investigated.

\section{Materials and methods}

\subsection{Preparation of calcium alginate beads}

Sodium alginate was dissolved in distilled water at a concentration of $3 \mathrm{wt} . \%$. After sodium alginate was completely dissolved, the solution was left undisturbly for 30 minutes to eliminate the air bubbles. The solution was then dropped from a height of $20 \mathrm{~cm}$ into gelling medium of $0.2 \mathrm{M}$ calcium chloride solution using a syringe with a needle. On the principle of simple ion exchange water soluble sodium alginate was converted to water insoluble and stable calcium alginate salt. The formed beads were cured in the gelling medium for $30 \mathrm{~min}$.

Calcium alginate beads were divided to three groups:

Gel beads: fresh prepared calcium alginate beads were washed with distilled water and used for experiments. The average size of the bead was found to be $3.03 \mathrm{~mm}$.

Dry beads A: prepared calcium alginate beads were rinsed with distilled water, dried and dipped in distilled water for 5 days. The average size of the bead was found to be $1.02 \mathrm{~mm}$.

Dry beads B: prepared calcium alginate beads were rinsed with distilled water and dried, resulting in particles with a diameter of $0.89 \mathrm{~mm}$.

\subsection{Study of the prepared beads stability}

The concentrated and diluted solutions of hydrochloric, nitric and sulphuric acids and sodium and potassium hydroxides were prepared. $\mathrm{pH}$ values were measured for each solution.

Approximately 8-16 beads from each fraction were immersed in the tubs with 10 $\mathrm{ml}$ of acidic and basic solutions and stored at laboratory temperature and changes in the form of beads were observed. 
During the whole experiment average diameter of beads were measured by using the micrometer screw gauge and these data were used for $\%$ volume change calculation according to the formula:

$$
V_{c}=\frac{V_{f}-V_{i}}{V_{i}} .100
$$

where $V_{c}$ - volume change [\%]

$V_{f}$ - final volume $\left[\mathrm{mm}^{3}\right]$

$V_{i}$ - initial volume $\left[\mathrm{mm}^{3}\right]$

\subsection{Preparation of immobilized algae in calcium alginate beads}

Powder prepared from dried alga Chlorella kessleri was mixed with 3\% sodium alginate solution in the ration 1:9. Immobilized beads were prepared with the same technique like calcium alginate beads (in section 2.1). Prepared beads were consequently divided into three groups.

A gel immobilized beads (stored in distilled water)

B dry immobilized beads before using dipped in distilled water for 12 hours

C dry immobilized beads

\subsection{Copper biosorption experiments}

Immobilized algae were used for biosorption of $\mathrm{Cu}^{2+}$ ions from solution with initial concentration $140 \mathrm{mg} \mathrm{l}^{-1}$. $\mathrm{pH}$ value of used solutions was 5.00. Each fraction (A, B, C) of beads at concentration $2 \mathrm{~g} \mathrm{l}^{-1}$ of beads were added into the solutions. These solutions were mixed during 24 hours. At selected time intervals, solution samples were withdrawn for metal analysis. The concentration of $\mathrm{Cu}^{2+}$ ions was measured by atomic absorption spectroscopy (Varian AA20+).

The metal uptake $q$ was calculated from the mass balance equation as follows:

$$
q=\frac{V\left(C_{0}-C_{e}\right)}{m}
$$

where $q$ - the quantity of metal uptake by biomass [mg g $\left.{ }^{-1}\right]$

$C_{0}$ - the initial metal concentration $\left[\mathrm{mg} \mathrm{l}^{-1}\right]$

$C_{\mathrm{e}}$ - final (after sorption at equilibrium) metal concentration $\left[\mathrm{mg} \mathrm{l}^{-1}\right]$

$V$ - the volume of solution [1]

$m$ - dry weight of the biomass added [g]

\section{Results and discussion}

\subsection{Calcium alginate beads stability}

Obtained characteristics of the behaviour in acidic conditions are shown for gel beads (Table 1) and dry beads (Table 2-3). The changes of the gel beads and dry beads in the basic solutions are listed in Table $4-6$. 
Table 1. $\mathrm{pH}$ values of the acidic solutions, average diameter of the beads, their volume with \% volume change before and at the end of experiment with gel beads. Initial diameter and initial volume of beads were $3.03 \mathrm{~mm}$ and $14.57 \mathrm{~mm}^{3}$, respectively.

\begin{tabular}{lcccccc}
\hline $\mathrm{pH}$ of the solution & $\mathrm{HCl}$ & $\mathrm{HNO}_{3}$ & $\mathrm{H}_{2} \mathrm{SO}_{4}$ & $\mathrm{HCl}$ & $\mathrm{HNO}_{3}$ & $\mathrm{H}_{2} \mathrm{SO}_{4}$ \\
\hline initial & 1.13 & 1.14 & 1.29 & 2.64 & 2.78 & 2.79 \\
with gel beads & 1.13 & 1.14 & 1.3 & 3.23 & 3.34 & 3.32 \\
\hline diameter of beads [mm] & 2.82 & 2.38 & 2.25 & 3.6 & 3.5 & 3.9 \\
volume [mm ${ }^{3}$ ] & 11.74 & 7.06 & 5.96 & 24.43 & 22.45 & 31.06 \\
volume change [\%] & $\mathbf{- 1 9 . 4}$ & $\mathbf{- 5 1 . 5}$ & $\mathbf{- 5 9 . 1}$ & $\mathbf{6 7 . 7}$ & $\mathbf{5 4 . 1}$ & $\mathbf{1 1 3 . 2}$ \\
\hline
\end{tabular}

Table 2. $\mathrm{pH}$ values of the acidic solutions, average diameter of the beads, their volume with \% volume change before and at the end of experiment with dry beads A. Initial diameter and initial volume of beads were $1.02 \mathrm{~mm}$ and $0.56 \mathrm{~mm}^{3}$, respectively.

\begin{tabular}{lcccccc}
\hline $\mathrm{pH}$ of the solution & $\mathrm{HCl}$ & $\mathrm{HNO}_{3}$ & $\mathrm{H}_{2} \mathrm{SO}_{4}$ & $\mathrm{HCl}$ & $\mathrm{HNO}_{3}$ & $\mathrm{H}_{2} \mathrm{SO}_{4}$ \\
\hline initial & 1.13 & 1.14 & 1.29 & 2.64 & 2.78 & 2.79 \\
with dry beads A & 1.15 & 1.15 & 1.31 & 3.77 & 3.68 & 3.99 \\
\hline diameter of beads [mm] & 1.30 & 1.23 & 1.30 & 1.07 & 1.07 & 1.03 \\
volume $\left[\mathrm{mm}^{3}\right.$ ] & 1.15 & 0.97 & 1.15 & 0.64 & 0.64 & 0.57 \\
volume change [\%] & $\mathbf{1 0 7}$ & $\mathbf{7 5 . 4}$ & $\mathbf{1 0 7}$ & $\mathbf{1 5 . 4}$ & $\mathbf{1 5 . 4}$ & $\mathbf{3}$ \\
\hline
\end{tabular}

Table 3. $\mathrm{pH}$ values of the acidic solutions, average diameter of the beads, their volume with \% volume change before and at the end of experiment with dry beads B. Initial diameter and initial volume of beads were $0.89 \mathrm{~mm}$ and $0.37 \mathrm{~mm}^{3}$, respectively.

\begin{tabular}{lcccccc}
\hline $\mathrm{pH}$ of the solution & $\mathrm{HCl}$ & $\mathrm{HNO}_{3}$ & $\mathrm{H}_{2} \mathrm{SO}_{4}$ & $\mathrm{HCl}$ & $\mathrm{HNO}_{3}$ & $\mathrm{H}_{2} \mathrm{SO}_{4}$ \\
\hline initial & 1.13 & 1.14 & 1.29 & 2.64 & 2.78 & 2.79 \\
with dry beads B & 1.14 & 1.14 & 1.3 & 3.66 & 3.54 & 3.62 \\
\hline diameter of beads [mm] & 1.23 & 1.3 & 1.34 & 1.17 & 1.05 & 1.04 \\
volume [mm ${ }^{3}$ ] & 0.97 & 1.15 & 1.26 & 0.84 & 0.61 & 0.59 \\
deviation [\%] & $\mathbf{1 6 4 . 0}$ & $\mathbf{2 1 1 . 6}$ & $\mathbf{2 4 1 . 3}$ & $\mathbf{1 2 7 . 2}$ & $\mathbf{6 4 . 2}$ & $\mathbf{5 9 . 6}$ \\
\hline
\end{tabular}

Table 4. $\mathrm{pH}$ values of the basic solutions, average diameter of the beads, their volume with \% volume change before and at the end of experiment with gel beads. Initial diameter and initial volume of beads were $3.03 \mathrm{~mm}$ and $14.57 \mathrm{~mm}^{3}$, respectively.

\begin{tabular}{lcccc}
\hline $\mathrm{pH}$ of the solution & $\mathrm{KOH}$ & $\mathrm{NaOH}$ & $\mathrm{NaOH}$ & $\mathrm{KOH}$ \\
\hline initial & 10.73 & 11.12 & 12.73 & 12.98 \\
with gel beads & 8.07 & 8.33 & 12.04 & 12.36 \\
\hline diameter of beads [mm] & 3.6 & 4.1 & dissolved by 3 days \\
volume [mm ${ }^{3}$ ] & 24.43 & 36.09 & & \\
volume change [\%] & $\mathbf{6 7 . 7}$ & $\mathbf{1 4 7 . 8}$ & & \\
\hline
\end{tabular}

From the presented results it is obvious that diameter and volume of the gel and dry beads of all groups in diluted acidic solutions of $\mathrm{HCl}, \mathrm{HNO}_{3}, \mathrm{H}_{2} \mathrm{SO}_{4}$ and in concentrated and diluted acidic solutions of $\mathrm{NaOH}, \mathrm{KOH}$ have increased in comparison with initial state and exhibited the tendency to swell. The dry beads B in 
concentrated solutions of the acids reached the highest swelling. From Table 2 it is visible that the dry beads $\mathrm{A}$ in diluted acidic solutions with $\mathrm{pH}$ values 2.64-2.79 have showed out minimal volume changes - from 3-15.4\%. The dry beads for both groups were more swelled in concentrated acidic solutions than in diluted acidic solutions. In according to HOFFMAN (2002) swelling of hydrogels is mainly attributed to the hydration of the hydrophilic groups of alginate. Also in this study is assumed that diluted acidic solution penetrates inside the beads in order to fill the inert pores among the polymer chains. After obtaining of maximum swelling degree dry and gel beads began indicate dissolution or degradation.

Table 5. $\mathrm{pH}$ values of the basic solutions, average diameter of the beads, their volume with \% volume change before and at the end of experiment with dry beads A. Initial diameter and initial volume of beads were $1.02 \mathrm{~mm}$ and $0.56 \mathrm{~mm}^{3}$, respectively.

\begin{tabular}{lcccc}
\hline $\mathrm{pH}$ of the solution & $\mathrm{KOH}$ & $\mathrm{NaOH}$ & $\mathrm{NaOH}$ & $\mathrm{KOH}$ \\
\hline initial & 10.73 & 11.12 & 12.73 & 12.98 \\
with dry beads A & 8.02 & 8.43 & 12.24 & 11.5 \\
\hline diameter of beads [mm] & 1.13 & 1.25 & dissolved by 3 days \\
volume [mm ${ }^{3}$ ] & 0.76 & 1.02 & & \\
volume change [\%] & $\mathbf{3 6}$ & $\mathbf{8 4 . 1}$ & & \\
\hline
\end{tabular}

Table 6. $\mathrm{pH}$ values of the basic solutions, average diameter of the beads, their volume with \% volume change before and at the end of experiment with dry beads B. Initial diameter and initial volume of beads were $0.89 \mathrm{~mm}$ and $0.37 \mathrm{~mm}^{3}$, respectively.

\begin{tabular}{lcccc}
\hline $\mathrm{pH}$ of the solution & $\mathrm{KOH}$ & $\mathrm{NaOH}$ & $\mathrm{NaOH}$ & $\mathrm{KOH}$ \\
\hline initial & 10.73 & 11.12 & 12.73 & 12.98 \\
with dry beads B & 7.96 & 8 & 12 & 11.53 \\
\hline diameter of beads $[\mathrm{mm}]$ & 1.1 & 1.1 & dissolved by 4 days \\
volume $\left[\mathrm{mm}^{3}\right.$ ] & 0.70 & 0.70 & & \\
deviation $[\%]$ & $\mathbf{8 8 . 8}$ & $\mathbf{8 8 . 8}$ & & \\
\hline
\end{tabular}

The changes of $\mathrm{pH}$ values were observed in the all solutions, excepting the concentrated acidic solutions. $\mathrm{pH}$ values in acidic solutions were higher and in alkaline solutions were lower after the swelling of calcium alginate beads. Whether with gel or with dry beads, $\mathrm{pH}$ values in concentrated acidic solutions remained without changes.

The gel and dry beads were dissolved by 3 days in concentrated solutions of sodium and potassium hydroxides. Observed degradability of alginate beads is caused by the presence of high concentrations of non-gelling ions, such as $\mathrm{Na}^{+}$and $\mathrm{K}^{+}$ (BAJPAI and SHARMA, 2004). The swelling mechanism and subsequent degradation of the beads in presence of the solution of $\mathrm{NaOH} / \mathrm{KOH}$ is related with the $\mathrm{Ca}^{2+}$ and $\mathrm{Na}^{+} / \mathrm{K}^{+}$exchange.

The gel beads tended to shrink when exposed to the concentrated acidic solutions of $\mathrm{HCl}, \mathrm{HNO}_{3}$ and $\mathrm{H}_{2} \mathrm{SO}_{4}$ (Table 1). At low $\mathrm{pH}$ values the carboxylic groups of alginate are protonized and hence the electrostatic repulsion among these groups lessens and shrinkage is favoured (HOFFMAN, 2002; PASPARAKIS and BOUROPOULOS, 2006). 


\subsection{Application of immobilized algae for the removal of $\mathrm{Cu}^{2+}$ heavy metal ions from aqueous solutions}

The results obtained from kinetic studies on $\mathrm{Cu}^{2+}$ sorption by immobilized algal beads of group A, B and C are shown in Fig. 1.

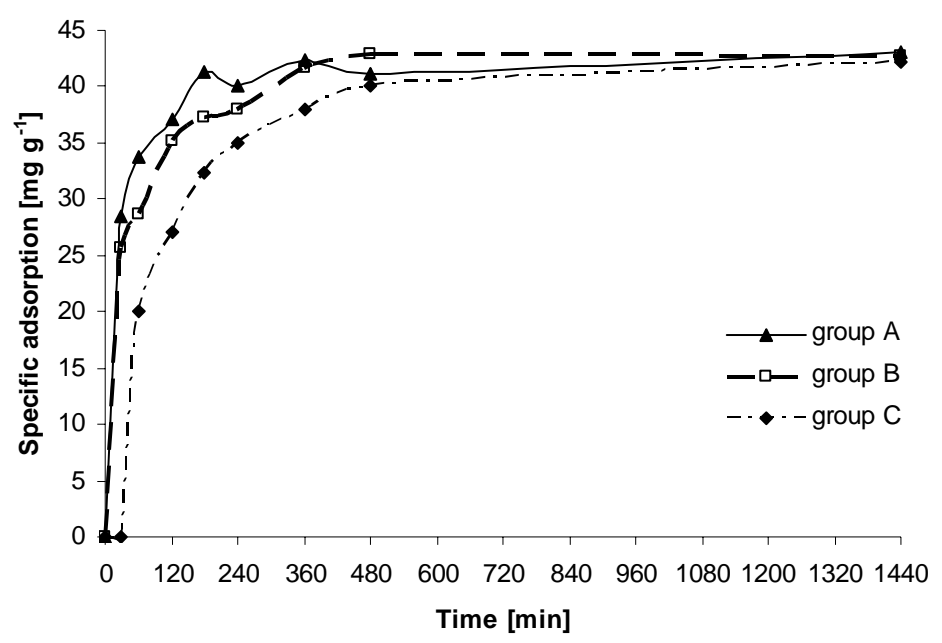

Fig. 1. Specific adsorption of copper solutions by immobilized algal beads of groups A, B, C.

It can be seen that biosorption capacity expressed as specific adsorption (q) has reached $33.8 \mathrm{mg} \mathrm{g}^{-1}$ of $\mathrm{Cu}^{2+}$ ions $(50 \%)$ in first hour during the experiment when gel beads $\mathrm{A}$ were used. When beads from group $\mathrm{B}$ and $\mathrm{C}$ were used specific adsorption capacity $35 \mathrm{mg} \mathrm{g}^{-1}$ of $\mathrm{Cu}^{2+}$ ions from model solutions took 2 and 4 hours for beads from group B and C, respectively. Group A and B reached equilibrium after 6 hours of biosorption. Group $\mathrm{C}$ reached equilibrium within 8 hours. After 24 hours all group A, $\mathrm{B}$ and $\mathrm{C}$ removed $63 \% \mathrm{Cu}^{2+}$ ions from solutions and it corresponds with specific adsorption capacity $43 \mathrm{mg} \mathrm{g}^{-1}$ of $\mathrm{Cu}^{2+}$ ions. From these results seems to be the fastest biosorption by gel beads from group A. On the other site dry beads from group B and $\mathrm{C}$ had higher mechanical stability. Kinetics of biosorption of $\mathrm{Cu}^{2+}$ ions by immobilized algae was compared with free powdered algae Chlorella kessleri (HORVÁTHOVÁ et al., 2008). In the case of using free powdered algae equilibrium was reached within 10 minutes and the biosorption capacity was $46.6 \mathrm{mg} \mathrm{g}^{-1}$ of $\mathrm{Cu}^{2+}$ ions.

\section{Conclusions}

This study shows that the stability of calcium alginate beads depends on $\mathrm{pH}$ values of the aqueous solutions and the initial physical state of the beads.

Behaviour of gel or dry beads is interesting because of the influence of individual metal ions in solutions. Calcium alginate beads are sensitive to the solutions 
containing sodium and/or potassium ions. In these solutions they are swelled and subsequently dissolved by ion-exchange process taking place between $\mathrm{Na}^{+} / \mathrm{K}^{+}$ions in solution and $\mathrm{Ca}^{2+}$ ions in the beads. Their presence is the limiting factor for utilization of calcium alginate in metal biosorption.

Dry beads A treated with diluted acidic solutions exhibited minimum swelling and they are the most preferable in bioreactors because of their high mechanical stability.

In contrast to the dry beads with the minimal swelling, the beads with tendency to increase are suitable when swelling and dissolution of the gels is required - an important factor in all applications where recovery of the cells is essential.

This study proved the practical feasibility of using immobilized algal beads for the removal of copper from aqueous solution. From studied groups of immobilized algal beads are gel immobilized beads the most suitable because of the fastest copper removal from model solutions.

Acknowledgement: This work was supported by VEGA 1/0134/09.

\section{References}

BAJPAI, S.K., SHARMA, S.: Investigation of swelling/degradation behaviour of alginate beads crosslinked with $\mathrm{Ca}^{2+}$ and $\mathrm{Ba}^{2+}$ ions. React. Funct. Polym., 59, 2004, 129-140.

HOFFMAN, A.S.: Hydrogels for biomedical applications. Adv. Drug Deliv. Rev., 43, 2002, 3-12.

HORVÁTHOVÁ H., KADUKOVÁ J., MRAŽÍKOVÁ A., SLAFKOVSKÁ, G., ŠTOFKO M.: Effect of nickel on copper and zinc biosorption. In: Acta Metallurgica Slovaca, 14, special issue, $1 / 2008,5^{\text {th }}$. International conference (Kammel's Quo Vadis Hydrometallurgy 5) Košice, 19.-22.may, 2008, 78-82.

KADUKOVÁ, J., ŠTOFKO, M.: Environmentálne biotechnológie pre hutníkov, KNKaSO HF TU v Kosiciach, Košice, 2006, 141 pp.

KADUKOVÁ, J., HORVÁTHOVÁ, H., MRAŽÍKOVÁ, A., ŠTOFKO, M.: Biosorption of $\mathrm{Cu}, \mathrm{Ni}$ and $\mathrm{Zn}$ from single metal solutions and their mixture by alga Chlorella kessleri, e-proceedings from 4th European Bioremediation Conference, Chania, Greece, September 3-6, 2008, ID188.

PASPARAKIS, G., BOUROPOULOS, N.: Swelling studies and in vitro reklease of verapamil from calcium alginate and calcium alginate-chitosan beads. Int. J. Pharm., 323, 2006, 34-42.

VIJAYA, Y., POPURI, S.R., BODDU, V.M., KRISHNAIAH, A.: Modified chitosan and calcium alginate biopolymer sorbents for removal of nickel (II) through adsorption. Carbohydr. Polymer., 72, 2008, 261-271.

VOLESKY, B.: Biosorption of heavy metals I. CRC Press, Inc., Boston, 1990, 381 pp.

VOLESKY, B.: Sorption and biosorption, BV Sorbex, Inc., Montreal, 2003, 316 pp.

VREEKER R., LI L., FANG Y., APPELQVIST I., MENDES E.: Drying and Rehydration of calcium Alginate Gels. Food Biophys., 3, 2008, 361-369.

WANG, J., CHEN, C.: Biosorbents for heavy metals removal and their future. Biotechnol. Adv., 27, 2009, 195-226. 